\title{
Model of the Heavy Freight Vehicle's Running Speed Used for Diversion Traffic Routes Determination
}

\author{
Jiř́ Hanzl $^{1, *}$, and Ladislav Bartuška ${ }^{2}$ \\ ${ }^{1}$ Institute of Technology and Business in České Budějovice, Faculty of Technology, Okružní 517/10, \\ 37001 České Budějovice, Czech Republic \\ ${ }^{2}$ Czech Technical University in Prague, Faculty of Transportation Sciences, Department of Logistics \\ and Management of Transport, Horská 2040/3, 12800 Prague, Czech Republic
}

\begin{abstract}
This paper describes the construction process of a discrete model of a heavy truck running speed. The running speed calculation is based on the technical parameters of the road (geometry, gradient, curves, etc.) and valid Czech legislation for road designing. In this article, road factors influencing the final heavy freight vehicle's running speed are presented as well. The main assumption is the fact that every heavy vehicle moves on the road by speed allowed by the geometry of this road, road signs and traffic flow characteristics (intensity, density or road capacity).
\end{abstract}

\section{Introduction}

A heavy freight vehicle (truck) is the most limiting factor in road traffic planning and when designing roads. That's why we're talking about this vehicle as a "design (determinant) vehicle". In the case of increased traffic volume, the traffic flow of vehicles on the road without the possibility of overtaking or on the road with the limited overtaking ability is at just the same speed as the speed of the heavy freight vehicle. If we want to determine the current speed of this vehicle at each point(s) of the road, we must take into account, in addition to the valid Czech legislation, also its own road geometry and traffic constraints on the road.

In order to describe the issue, the authors created a professional search detailing the individual factors on the road influencing the speed of the heavy freight vehicle. In addition to the maximum permitted driving speed, additional constraints are considered, such as railway crossings, road geometry parameters, etc. The text of the paper is based mainly on the thesis entitled "Determination of alternative routes of main roads in the event of extraordinary and planned traffic constraints", where the whole issue is described in more detail and the outcome of which is the analytical model for valuation of diversion traffic routes according to their impedance [1]. This discrete model also uses, in addition to the driving dynamics of a selected type of vehicle, the road geometry parameters (directional

* Corresponding author: hanzl@mail.vstecb.cz 
ratios, curve radius, width arrangement, etc.) and maximum permitted speed on the road section supplemented by other decision criteria.

\section{Running speed calculation model}

For the determination of the vehicle's running speed on the road, the so-called determinant slow vehicle is considered because, as already described in the introductory part of the paper, it is the most limiting factor of the entire traffic flow. According to the Czech technical standards as a design determinant vehicle is considered the vehicle with a total weight of 44 tonnes, with a totally variable ratio continuously variable in the range from 2.070 to 49.680 (with regard to the optimal working conditions of the engine unit), with a radius of $0.526 \mathrm{~m}$, the efficiency of the transmission unit 0.8888 , air resistance coefficient 0.7 , coefficient of rolling resistance 0.006 , and engine driving torque $1600 \mathrm{Nm}$ (for ascending route), $0 \mathrm{Nm}$ (free run) and $-550 \mathrm{Nm}$ (for braking) [2-4].

The input parameters of the calculation, which have a significant influence on the resulting running speed of the determinant slow vehicle on a given segment of the road, are given in Table 1. Segmentation of a road means its division into separate sections with a similar character of traffic, whereby the calculation model selects a minimum speed on the given road segment (or maximum speed limit). This velocity is the standard rate at which the entire traffic flow will move [5].

Table 1. Input parameters of the calculation based on the geometry of the road, the legislative regulations and the characteristics of the traffic flow. Source: [1]

\begin{tabular}{|l|c|}
\hline a) width of road traffic lane & $\mathrm{a}[\mathrm{m}]$ \\
\hline b) directional conditions of the road (curve radius) & $\mathrm{R}[\mathrm{m}]$ \\
\hline c) vertical alignment of road (longitudinal slope) & $\mathrm{s}[\%]$ \\
\hline d) maximal allowed speed on the road & $\mathrm{V}_{\mathrm{vk}}[\mathrm{km} / \mathrm{h}]$ \\
\hline e) speed restrictions on the road & $\mathrm{v}_{\mathrm{om}}[\mathrm{km} / \mathrm{h}]$ \\
\hline f) traffic restrictions for heavy freight vehicles on the road & \\
\hline g) estimated traffic intensity on the road & $\mathrm{I}[\mathrm{cars} / \mathrm{h}]$ \\
\hline
\end{tabular}

The selected parameters in Table 1 are described in more detail in the following sections of the paper.

\section{Parameters that influence the driving speed}

\subsection{Width of the road traffic lane a [m]}

The wide-lane arrangement of the road is an important parameter for the determination of design (determinant) speed in road design. To determine the running speed depending on the width of the lane of the road, the table 2 is used [2]. 
Table 2. Design speed dependence on the road driving lane width. Source: [2]

\begin{tabular}{|c|c|c|c|c|}
\hline \multicolumn{4}{|c|}{ Design category of road } & Driving lane \\
\hline Designation & $b[\mathrm{~m}]$ & Design speed $v_{n}[\mathrm{~km} / \mathrm{h}]$ & Road class & $a[m]$ \\
\hline $\mathrm{S}$ & 6.5 & 60 & III. & 2.75 \\
\hline $\mathrm{S}$ & 7.5 & 70 & II., III. & 3.00 \\
\hline $\mathrm{S}$ & 9.5 & 80 & I., II. & 3.50 \\
\hline $\mathrm{S}$ & 11.5 & 90 & I. & 3.50 \\
\hline
\end{tabular}

\subsection{Directional conditions of the road (curve radius) $R[\mathrm{~m}]$}

Directional curve radius is one of the most important parameters of the infrastructure, which significantly affects the vehicle speed passing vehicles the road turning. In simplified calculations, the authors consider a simple circular arc without transitions, for which the following formula can be used to calculate the limit speed $v_{m}$ which is still possible to pass safely the road bend with vehicle [6]. Together with the size of the radius $R$, the gravitational acceleration $g$ and the cross slope of the road $p$ are added to the calculation [5].

The general formula for limiting speed calculation has the following form:

$$
v_{m}=3.6 \cdot \sqrt{g \cdot R \cdot(f+0.01 \cdot p)},
$$

where: $v_{m}$ - limit velocity $[\mathrm{km} / \mathrm{m}] ; R$ - directional curve radius $[\mathrm{m}] ; f$ - adhesion coefficient value (for the calculation of the achievable speed, the value $\mathrm{f}=0.25$ ) $[\mathrm{m}] ; p$ - cross slope (if there is an opposite cross slope in the directional curve, the negative value is set) $[\%] ; \mathrm{g}$ gravitational acceleration $9.81\left[\mathrm{~m} / \mathrm{s}^{2}\right][6]$.

\subsection{Vertical alignment of road (longitudinal slope) $s[\%]$}

The calculation of the running speed of the design (determinant) vehicle is based on the pictorial annex "K2 - Relationship between the longitudinal tilt of the vehicle and the speed of the design vehicle for the other road network (with initial speed $70 \mathrm{~km} / \mathrm{h}$ )" of standard [2]. Since the change in velocity depending onthe size of the longitudinal slope is not characterized by a linear curve, it is necessary to linearize these curves (Figure 1) to express the rate of change of velocity depending on the length of the section at which this change occurred. By setting the initial velocity $v_{0}[\mathrm{~km} / \mathrm{h}]$, the convergence velocity $v_{k}[\mathrm{~km} / \mathrm{h}]$, the velocity change coefficient $\Delta v\left[s^{-1}\right]$ and the length of the road section $l_{k}[\mathrm{~m}]$ into the uniformly accelerated motion equation, it is possible to calculate the average velocity of the slow vehicle due to the longitudinal slope of the road $v_{s}[\mathrm{~km} / \mathrm{h}][8]$. 


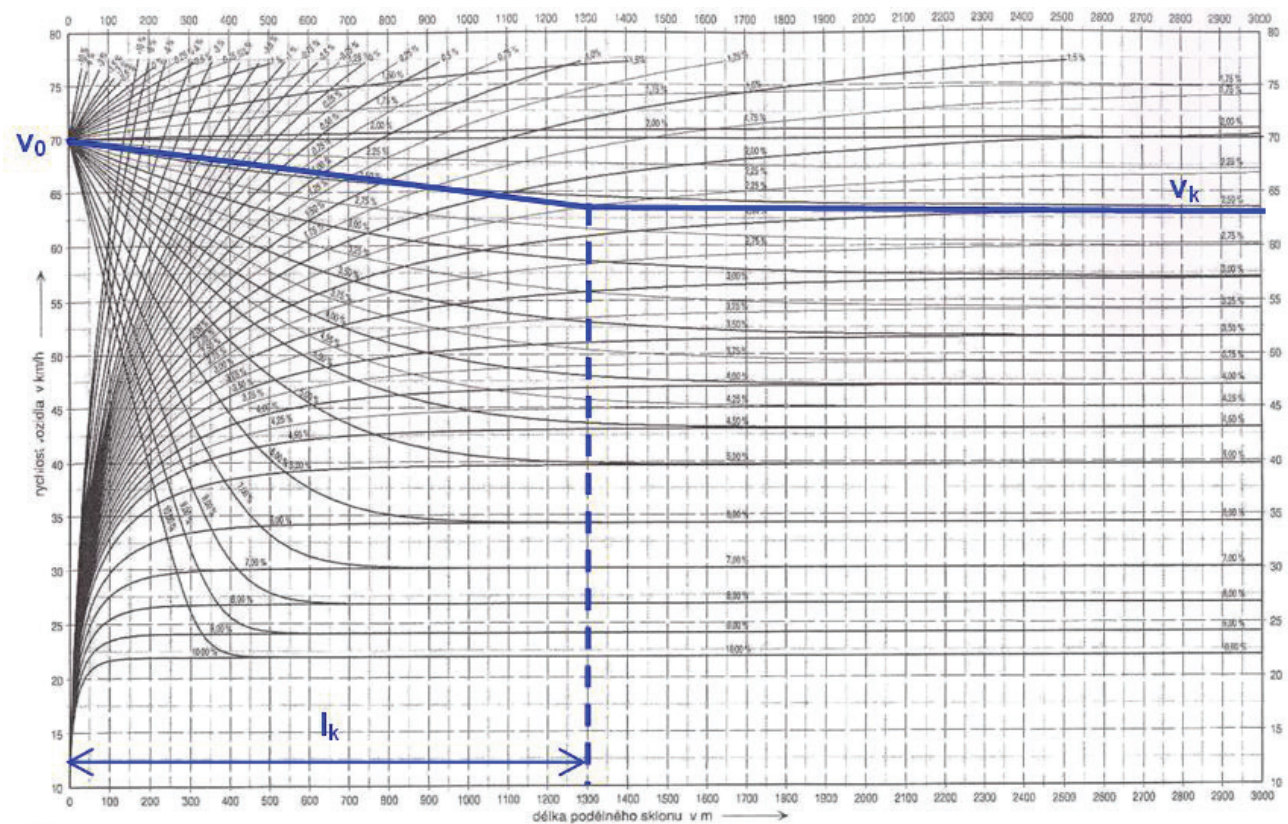

Fig. 1. Linearization of curves expressing the relationship of the longitudinal slope of the road and the vehicle speed. Source: [1]

\subsection{Maximal allowed speed on the road $v_{v k}[\mathrm{~km} / \mathrm{h}]$}

In the Czech Republic, according to [7], the maximum permitted speed of heavy freight vehicles on free road is determined without speed restrictions according to Table 3:

Table 3. The highest allowed speed of heavy freight vehicles on roads in the Czech Republic. Source: [2]

\begin{tabular}{|c|c|c|}
\hline designation of the road & $v_{v k}[\mathrm{~km} / \mathrm{h}]-$ extravilan & $v_{v k}[\mathrm{~km} / \mathrm{h}]-$ urban area \\
\hline D & $80 \mathrm{~km} / \mathrm{h}$ & $50-80 \mathrm{~km} / \mathrm{h}$ \\
\hline S I, II, III & $80 \mathrm{~km} / \mathrm{h}$ & $50-80 \mathrm{~km} / \mathrm{h}$ \\
\hline MK & $80 \mathrm{~km} / \mathrm{h}$ & $50-80 \mathrm{~km} / \mathrm{h}$ \\
\hline
\end{tabular}

\subsection{Speed limit on road section $v_{o m}[\mathrm{~km} / \mathrm{h}]$}

Speed restrictions on the road may be represented by vertical traffic signs or railway crossings. For example, in the case of a railway-road crossing, it is necessary to base the limit speed on valid legislation on road traffic. If there is a railway-road crossing with a light signal system (if the intermittent white signal of the signalling device is flashing), the driver of vehicle has to drive in the distance of $50 \mathrm{~m}$ from the railway crossing and when passing the crossing at speed of not more than $50 \mathrm{~km} / \mathrm{h}$. In the case of no controlled railway-road crossing without light signal devices or the device is off, the driver may drive in the distance $50 \mathrm{~m}$ from the railway crossing and when passing the railway crossing at a speed not exceeding $30 \mathrm{~km} / \mathrm{h}$. 


\subsection{Other road traffic restrictions for heavy freight vehicles}

To calculate the driving speed of heavy freight vehicles, it is important that the driving of such vehicles on the road section is not prohibited or otherwise restricted. If there is any such traffic constraint, mostly determined by traffic signs, there is no point in continuing to calculate the driving speed. For example traffic signs "No entry for trucks" or "No entry for vehicles which immediate weight exceeds the limit indicated", and others [9].

\subsection{Estimated traffic intensity on the road I [cars/hour]}

The last input parameter of the calculation, based on the traffic characteristics of the traffic flow, is the traffic intensity $I$. With increasing intensities (traffic volumes), individual vehicles will interact with each other during the ride, which will affect the resulting speeds of the entire traffic flow. Not only the geometric parameters of the road and the traffic constraints on the route (and the calculated maximum limit speeds), but also the total traffic flow intensity, will influence the resulting driving speed [10].

Level of Service (LOS, UKD in Czech) is a qualitative measure used to relate the quality of traffic service. LOS (UKD) is used to analyse highways and main roads by categorizing traffic flow and assigning quality levels of traffic based on performance measure like speed, density, etc. For Level of Service in the "E" category, with the minimum longitudinal slope and the minimum share of slow-moving vehicles, the following values apply to the two-lane road according to [2]:

Table 4. Traffic flow characteristics due to critical density for 2-lane road. Source: [1]

\begin{tabular}{|c|c|c|c|}
\hline Type of road & $\begin{array}{c}\text { Traffic density at LOS } \\
(\mathrm{UKD}) \text { in category "E" } \\
H_{\text {opt }}[\mathrm{cars} / \mathrm{km}]\end{array}$ & $\begin{array}{c}\text { Road capacity } \\
I_{\max }[\text { cars } / \text { hour }]\end{array}$ & $\begin{array}{c}\text { Optimal speed until } \\
\text { reaching road capacity } \\
v_{\text {opt }}[\mathrm{km} / \mathrm{h}]\end{array}$ \\
\hline 2 - lane road & $20 \mathrm{cars} / \mathrm{km}$ & 1250 cars $/$ hour & $62.5 \mathrm{~km} / \mathrm{h}$ \\
\hline
\end{tabular}

From the fundamental diagram (Figure 2) expressing the dependence of the velocity of the traffic flow on the intensity, it is obvious that this relation is parabolic. As the velocity increases, the traffic intensity increases until its maximum (road capacity $I_{\max }$ ) value is reached. Subsequently, despite the increase in velocity, the traffic intensity decreases again [11]. 


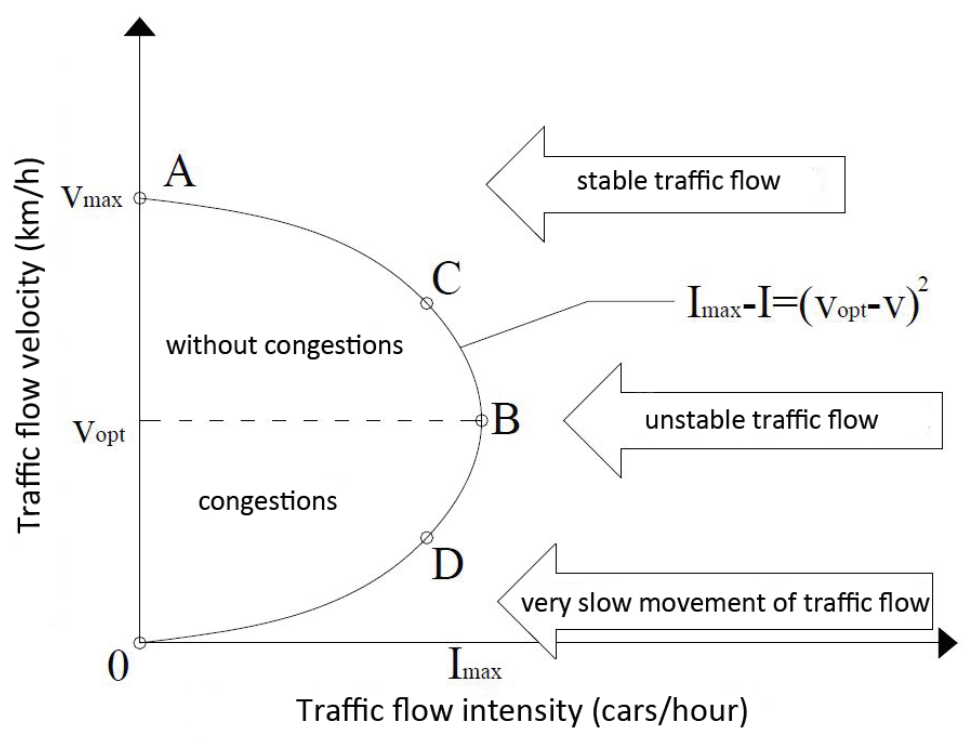

Fig. 2. Parabolic course of traffic flow velocity dependence on traffic intensity. Source: [11]

The parabola curve has the equation:

$$
I_{\max }-I=\left(v_{o p t}-v\right)^{2},
$$

Where $I_{\max }$ - maximal traffic intensity value (road/lane capacity) [cars/hour],

$I$ - current traffic intensity [cars/hour],

$v_{\text {opt }}$ - the optimal speed at which the traffic flow reaches its maximum intensity $I_{\text {max }}[\mathrm{km} / \mathrm{h}]$,

$v$ - current traffic flow velocity $[\mathrm{km} / \mathrm{h}] .[1]$

By adjusting the equation and setting up the variable values $I_{\max }$ a $v_{\text {opt }}$ from Table 4, we obtain the equation for calculating the velocity of the traffic flow on the selected road section as a function of the current traffic intensity:

$$
v_{I}=v_{o p t} \pm \sqrt{I_{\max }-I}
$$

Where $v_{I}$ - the traffic flow velocity on a given road section in one driving lane depending on traffic intensity $[\mathrm{km} / \mathrm{h}]$,

$v_{\text {opt }}$ - the optimal velocity at which the traffic flow reaches the maximum intensity $I_{\max }$ in one driving lane $[\mathrm{km} / \mathrm{h}]$,

$I_{\max }$ - maximal traffic intensity value (road/lane capacity) [cars/hour], $I_{\max }=1250$ cars $/$ hour

$I$ - current traffic intensity on given road section [cars/hour].

Based on the actual traffic density $H_{j}[\mathrm{voz} / \mathrm{km}]$ on the road in one driving lane and according to Fig. 2, the appropriate formula of calculation is selected according to the following:

1) $H_{j}<H_{\text {opt }} \quad v_{I, j}=62.5+\sqrt{1250-I}$,

2) $H_{j}=H_{o p t} \quad v_{I, j}=62.5$,

3) $H_{j}>H_{o p t} \quad v_{I, j}=62.5-\sqrt{1250-I} \cdot[1]$ 


\section{The calculation model output of the running speed of the heavy freight vehicle}

As mentioned above, the calculation model selects a minimum (maximum limiting) speed $v_{\min }$ on a given road section. Its schematic representation is given in Fig. 3. Therefore, the following will apply $[12,15]$ :

$$
v_{\text {min }}=\min \left\{v_{n} ; v_{m} ; v_{s} ; v_{v k} ; v_{o m} ; v_{I}\right\}
$$

Where $v_{\min }$ - minimum speed (or maximum limiting) on a given road section $[\mathrm{km} / \mathrm{h}]$, $v_{n}$ - design speed (for road designing) on a given road section $[\mathrm{km} / \mathrm{h}]$,

$v_{m}$ - limit speed on a given road section $[\mathrm{km} / \mathrm{h}]$,

$v_{s}$ - average speed due to the longitudinal slope of the road section $[\mathrm{km} / \mathrm{h}]$,

$v_{v k}-$ the highest allowed speed on a given road section $[\mathrm{km} / \mathrm{h}]$,

$v_{o m}$ - speed restrictions a given road section $[\mathrm{km} / \mathrm{h}]$,

$v_{I}$ - the traffic flow speed on a given road section in one driving lane depending on traffic intensity $[\mathrm{km} / \mathrm{h}]$.

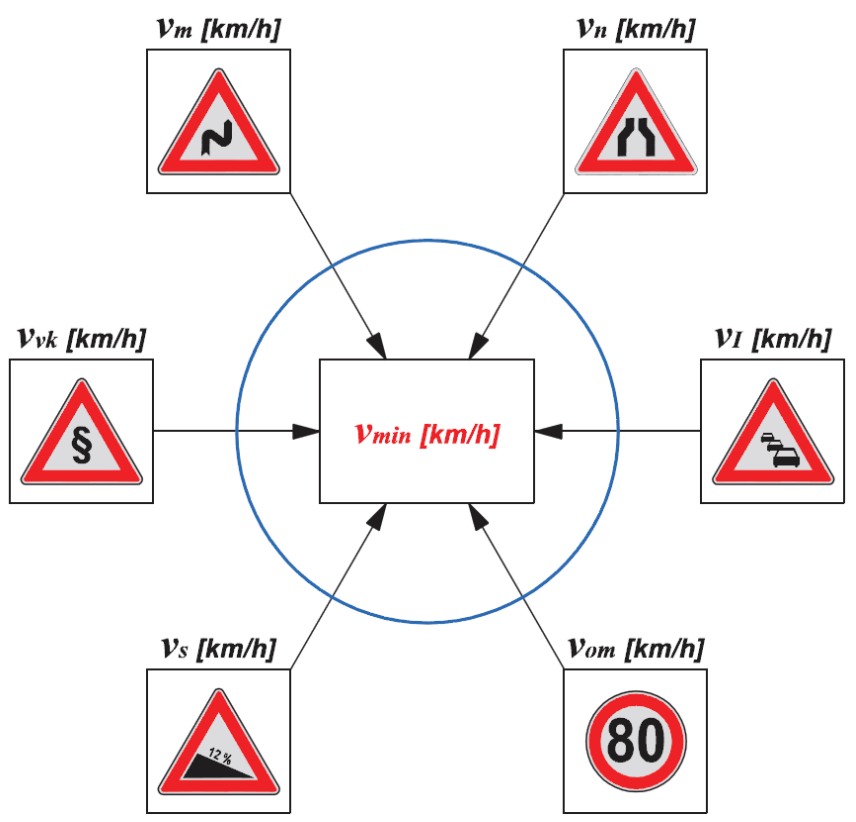

Fig. 3. Schematic representation of the maximum limiting speeds on a given road section. Source: authors

\section{Conclusion}

The main objective of this paper was to familiarize readers with the main factors influencing the resulting velocity of the heavy freight vehicle (determinant vehicle for road designing) as the most limiting factor of the entire traffic flow moving on the road section. The contribution describes the individual parameters (characteristics) directly affecting the freight vehicle driving speed. It is not only a legislative measure, but also a design parameters of the road and the characteristics of the traffic flow, which are described. As mentioned in chapters above, the text of the paper is based largely on [1], in which the 
whole issue is described in more detail as part of the so-called analytical model for peer assessment of roads, expressed in financial equivalence.

This paper is supported by the research project "From horse-drawn railway to intermodal transport" within Visegrad Fund.

\section{References}

1. J. Hanzl. Determination of alternative routes of main roads in the event of extraordinary and planned traffic constraints: dissertation (Czech Technical University in Prague, Faculty of Transportation Engineering, Czech Republic, 2017)

2. Czech Technical Standards CSN 73 6101, Designing of roads and highways

3. J. Vrabel, O. Stopka, V. Rievaj, B. Sarkan, K. Pruskova, P. Michalk, Communications: Scientific Letters of the University of Zilina 18, 2, 124-128 (2016)

4. F. Brumercik, M. Lukac, Logi - Scientific Journal on Transport and Logistics 3, 1, 4552 (2012)

5. J. Hanzl, et al. Transport Means - 20th International Scientific Conference on Transport Means, 354-360, (Juodkrante, Lithuania, 2016)

6. Czech Technical Standards CSN 73 6102, Z1: 2011, Design of intersections on roads.

7. (CZ) Act No. 361/2000 Coll. Road Traffic, as amended

8. M. Tomasikova, F. Brumercik, A. Nieoczym, Logi - Scientific Journal on Transport and Logistics 6, 1, 130-135 (2016)

9. R. Kampf, S. Lorincová, M. Hitka, O. Stopka, Sustainability 9, 9, 1561, (2017), DOI: 10.3390/su9091561

10. M. Hitka, L. Ližbetinová, Z. Caha, Y. Xu, Communications: Scientific Letters of the University of Zilina 18, 2 (2016)

11. A. Csikos,T. Charalambous, H. Farhadi, B. Kulcsar, H. Wymeersch, Transportation Research Part C: Emerging Technologies 83, 120-133 (2017)

12. L. Bartuška, J. Čejka, Z. Caha, Nase More 62, $91-96$ (2015), DOI:10.17818/NM/2015/SI1

13. J. Jagelčák, I. Kubasáková, Naše more 61, 5-6, 106-116 (2014)

14. O. Stopka, M. Chovancová, J. Ližbetin, V. Klapita, Nase More 63, 3, 195-199 (2016), DOI: $10.17818 / \mathrm{NM} / 2016 / \mathrm{SI} 22$.

15. G. Fedorko, V. Molnár, J. Strohmandl, M. Vasil', Transport Means - 19th International Scientific Conference on Transport Means, 466-469 (Kaunas University of Technology, Lithuania, 2015) 